\title{
Resource partitioning along multiple niche axes drives functional diversity in parrotfishes on Caribbean coral reefs
}

\author{
Thomas C. Adam $^{1,2} \cdot$ Megan Kelley $^{1} \cdot$ Benjamin I. Ruttenberg $^{3,4} \cdot$ Deron E. Burkepile $^{1}$
}

\begin{abstract}
The recent loss of key consumers to exploitation and habitat degradation has significantly altered community dynamics and ecosystem function across many ecosystems worldwide. Predicting the impacts of consumer losses requires knowing the level of functional diversity that exists within a consumer assemblage. In this study, we document functional diversity among nine species of parrotfishes on Caribbean coral reefs. Parrotfishes are key herbivores that facilitate the maintenance and recovery of coral-dominated reefs by controlling algae and provisioning space for the recruitment of corals. We observed large functional differences among two genera of parrotfishes that were driven by differences in diet. Fishes in the genus Scarus targeted filamentous algal turf assemblages, crustose coralline algae, and endolithic algae and avoided macroalgae, while fishes in the genus Sparisoma preferentially targeted macroalgae. However, species with similar diets
\end{abstract}

Thomas C. Adam

adam@lifesci.ucsb.edu

1 Marine Sciences Program, Department of Biological Sciences, Florida International University, North Miami, FL 33181, USA

2 Present Address: Marine Science Institute, University of California, Santa Barbara, CA 93106, USA

3 NOAA Fisheries, Southeast Fisheries Science Center, Miami, FL 33149, USA

4 Biological Sciences Department, California Polytechnic State University, San Luis Obispo, CA 93410, USA were dissimilar in other attributes, including the habitats they frequented, the types of substrate they fed from, and the spatial scale at which they foraged. These differences indicate that species that appear to be functionally redundant when looking at diet alone exhibit high levels of complementarity when we consider multiple functional traits. By identifying key functional differences among parrotfishes, we provide critical information needed to manage parrotfishes to enhance the resilience of coral-dominated reefs and reverse phase shifts on algal-dominated reefs throughout the wider Caribbean. Further, our study provides a framework for predicting the impacts of consumer losses in other species rich ecosystems.

\section{Introduction}

Ecosystems can undergo rapid transitions from a desirable state to a less desirable, degraded state with reduced capacity to provide important ecosystem services (e.g., regime shifts or phase shifts; Folke et al. 2004). These abrupt changes are frequently associated with the loss of key consumers that can lower the resilience of an ecosystem to natural and anthropogenic disturbances (Estes et al. 2011). However, in many systems, multiple consumers play similar roles, making it difficult to predict how the loss of any individual species will impact the overall structure and function of the ecosystem (Duffy 2002). This is especially true in species-rich systems such as tropical coral reefs and African savannahs, where dozens of consumers may perform similar ecological functions (Du Toit and Cumming 1999; Bellwood et al. 2004). 
On coral reefs, herbivorous fishes and sea urchins are critical for maintaining ecosystem function by controlling algae that can displace reef-building corals. Herbivores influence reef ecosystems through a variety of processes, including the provisioning of space for coral settlement (Steneck et al. 2014) and the removal of macroalgae that can slow coral growth and increase coral mortality (Burkepile and Hay 2008). Loss of key herbivores can result in persistent phase shifts from coral-dominated systems to algal-dominated systems with reduced levels of primary and secondary production (Carpenter 1986) and compromised capacity to build reefs and provision habitat for other organisms (Perry et al. 2013; Bozec et al. 2015). Consequently, overexploitation of herbivores in subsistence and commercial fisheries could compromise the function of reef ecosystems by reducing the total biomass of herbivores and by altering the species composition and size structure of the herbivore assemblage (Edwards et al. 2014).

Diversity of herbivorous fishes can be important for maintaining ecosystem function on coral reefs because herbivores that feed on different types of algae have complementary impacts on benthic communities (Bellwood et al. 2006; Burkepile and Hay 2008; Rasher et al. 2013). Species that feed on filamentous algal turfs and associated detritus can facilitate coral recruitment and maintain reefs in a coral-dominated state, while species that feed on mature macroalgae can prevent macroalgae from overgrowing corals and can help reverse phase shifts on macroalgal-dominated reefs. The level of overlap in the diets of different herbivores (i.e., redundancy vs. complementarity), therefore, provides a metric of the level of functional diversity present within the herbivore guild (Burkepile and Hay 2011). Guilds with higher levels of redundancy among species may be more resilient to overharvesting and better able to fulfil their ecological function. However, herbivores vary widely in a number of traits in addition to diet that will modulate their impacts on reef ecosystems and influence patterns of redundancy, including size (Lokrantz et al. 2008), movement patterns (Nash et al. 2013), preferred habitats (Robertson and Gaines 1986), and the specific substrates they target while foraging (Brandl and Bellwood 2014). Coexistence theory predicts that species that are similar in one niche dimension, such as diet, will be different in others, such as habitat selection (MacArthur and Levins 1967). Thus, there may be less functional redundancy within the herbivore guild than predicted by patterns of diet overlap alone when one considers the many other dimensions of the niches of these species.

Over the last several decades, many coral reef ecosystems throughout the wider Caribbean have experienced a phase shift (Hughes et al. 2010). On many reefs, large, structurally complex corals have been replaced by fleshy algae and other non-reef building organisms, resulting in the collapse of physical structure and the rapid loss of ecosystem function (Bruno et al. 2009; Hughes et al. 2010; Alvarez-Filip et al. 2011; Perry et al. 2013). The decline of Caribbean coral reefs has been linked to a variety of stressors such as climate change and compromised water quality, but the loss of herbivores due to overfishing and disease is likely a major contributor (Jackson et al. 2014). Although herbivore diversity in general appears important for facilitating healthy reefs (Burkepile and Hay 2008, 2010, 2011), we currently have a limited understanding of the level of functional diversity present within the herbivore guild (Adam et al. 2015a).

Here, we explored the level of functional redundancy versus complementarity that exists among herbivorous parrotfishes, the dominant grazers throughout much of the Caribbean (Mumby 2006). We used direct observation to document patterns of resource use for nine species of Caribbean parrotfishes. We then determined the extent that species attributes, such as phylogenetic history and body size, predict differences in foraging traits. We found that species that feed on similar types of algae often prefer different habitats, feed from different substrates, and forage at different spatial scales, indicating low levels of functional redundancy in the parrotfish guild. This information is crucial when managing parrotfishes for their capacity to prevent and reverse phase shifts to macroalgal dominance and facilitate corals.

\section{Materials and methods}

\section{Organisms and study sites}

Parrotfishes belong to two monophyletic clades, represented on Caribbean coral reefs by two genera, Sparisoma and Scarus (Streelman et al. 2002). Sparisoma parrotfishes are often associated with seagrass habitats in addition to reefs. They exhibit a high diversity of foraging modes, with some species feeding primarily on seagrasses and macroalgae while others predominantly scrape and excavate algae from carbonate substrates. In contrast, Scarus parrotfishes are almost exclusively reef-associated, with all species apparently adapted to scrape or excavate epilithic algal turfs and endolithic algae from carbonate substrates (Bonaldo et al. 2014). Species from both genera vary greatly in size ( 2 orders of magnitude), and thus are likely to perform a range of different ecological functions.

This study was conducted during June and July 2013 in the Florida Keys National Marine Sanctuary (FKNMS) off of Key Largo, FL, USA. The Florida Keys Reef Tract consists of a large bank reef system located approximately $8 \mathrm{~km}$ offshore of the Florida Keys, USA, and paralleling the island chain. The FKNMS provided an ideal setting for 
this study. Fishing pressure on parrotfishes in the Florida Keys is very low (Bohnsack et al. 1994). As a result there are large populations of several species of parrotfishes that are rare or absent in many other locations, including the largest parrotfishes in the Caribbean, Scarus coelestinus, Scarus coeruleus, and Scarus guacamaia (Paddack et al. 2006).

We conducted fish surveys on four shallow, high-relief spur and groove reefs (Molasses, French, Carysfort, and Elbow), with behavioral observations conducted on three of these (Molasses, Carysfort, and Elbow). Spur formations consist of large coral outcrops that rise approximately 2-6 $\mathrm{m}$ from the seafloor. Outcrops are interspersed with a mixture of sand, carbonate boulders, and small coral rubble, substrates which also dominate the shallow areas inshore of the primary spur and groove habitat. Offshore of the main spur formations, reefs transition to a slightly deeper low-relief carbonate platform (Fig. S1). We conducted fish surveys, behavioral observations, and benthic surveys in all three habitats: high-relief spur and groove (depth 2-6 m), low-relief carbonate platform/hardbottom (depth 4-12 m), and carbonate boulder/rubble fields (depth 4-9 m).

\section{Parrotfish surveys}

At each site, we estimated parrotfish abundance in the three habitat types in order to assess the relative abundance and biomass of different species and to quantify differences in habitat selection. To estimate parrotfish density, we conducted 20-30 min timed swims while towing a GPS receiver on a float to measure the distance traveled and calculate the amount of area sampled. During a swim, the observer would swim parallel with the habitat type being sampled and count and estimate the size to the nearest $\mathrm{cm}$ of all parrotfishes $\geq 15 \mathrm{~cm}$ in length that were encountered in a 5-m-wide swath. The diver sampled multiple habitat types during each timed swim. Therefore, we divided the timed swims into 1-min intervals and recorded the habitat type during each interval (see Fig. S1b). The goal of the timed swims was to achieve similar sampling effort in each habitat type, and the method enabled us to sample $\sim 30,000 \mathrm{~m}^{2}$ of habitat, an area sufficiently large to obtain density estimates of all parrotfishes including less common species (see Table S1 for amounts of each habitat type sampled). We calculated biomass of each species using published length-weight relationships (Bohnsack and Harper 1988).

\section{Behavioral observations}

We characterized the diet and foraging behavior of the nine species of parrotfishes that account for $>99 \%$ of the parrotfish biomass on these reefs, Scarus coelestinus, Scarus coeruleus, Scarus guacamaia, Scarus taeniopterus, Scarus vetula, Sparisoma aurofrenatum, Sparisoma chrysopterum, Sparisoma rubripinne, and Sparisoma viride. Approximately 18 individuals of each species (range $=16-19$ ) were observed for $20 \mathrm{~min}$ each, with observations evenly distributed across three sites (see Table S2 for details). In order to control for diurnal variation in foraging behavior, we followed focal individuals in a balanced design in three 2-h sampling intervals (1000-1200, 1200-1400, and 1400-1600). This time period corresponds to peak feeding time for herbivorous fishes (e.g., Bruggemann et al. 1994). We focused on characterizing the behavior of large adults. For sexually dimorphic species, we limited observations to the initial phase (IP) because the IP individuals tend to be much more common than terminal phase individuals (Hawkins and Roberts 2003).

Focal individuals for behavioral observations were haphazardly selected using the following criteria. First, we planned our observations so that all species would be observed in the same general locations while also minimizing the potential for resampling the same individuals. We did this by following one individual of as many species as possible in a given location before moving to the next location. Second, we initiated our observations on or near high-relief habitat, which supported the highest density and biomass of most species. Third, we targeted the largest IP individuals we saw in these locations. After identifying a potential target individual, we approached the fish slowly and allowed $\sim 2-3$ min to acclimate to the presence of an observer. We estimated their size to the nearest $\mathrm{cm}$ and began observations. Fish usually acclimated quickly to the presence of an observer, but observations were occasionally aborted when fish did not resume normal foraging behavior. Foraging behavior was then recorded by a SCUBA diver for a period of 20 min while towing a GPS receiver (Garmin GPS 72) which obtained position fixes of the focal fish at 15 -s intervals.

Fish were followed from a close distance $(\sim 2 \mathrm{~m}$ when possible), and food items were identified to the lowest taxonomic level possible, with macroalgae and coral usually identified to genus or species. Many bites involved scraping or excavating substrate colonized by a multi-species assemblage of filamentous "turf" algae, crustose coralline algae (CCA), and associated detritus, commonly referred to as the epilithic algal matrix (EAM) (Wilson et al. 2003). Because it was impossible to determine the specific food items targeted, these bites were categorized as being on EAM.

We also recorded the type of substrate targeted during each foraging bout, categorizing each substrate as one of the following: (1) dead coral, (2) coral pavement, (3) boulder, (4) rubble, or (5) ledge. Dead coral included both 
convex and concave surfaces on the vertical and horizontal planes of three-dimensional coral skeletons (primarily dead Acropora palmata) that were attached to reef substrate. Coral pavement was carbonate reef with little topographic complexity (i.e., flat limestone pavement). Boulder was large remnants of dead mounding corals not clearly attached to the bottom and often partially buried in sand. Coral rubble consisted of small dead coral fragments (generally $<10 \mathrm{~cm}$ in any dimension) that could be moved with minimal force. Ledges consisted entirely of the undercut sides of large spurs in spur and groove habitat. In addition to recording foraging behavior, we also recorded other activities such as aggressive interactions with other fish.

\section{Characterization of the benthos}

To quantify the relative abundance of different food types, we estimated the percent cover of algae, coral, and other sessile invertebrates on each of the five substrates commonly targeted by parrotfishes (dead coral, coral pavement, boulder, rubble, or ledge) in $0.5 \mathrm{~m} \times 0.5 \mathrm{~m}$ photoquadrats. We photographed a total of eight haphazardly selected quadrats dispersed throughout the study site for each substrate type at each of the three sites $(N=24$ quadrats per substrate type, $N=120$ quadrats total). Each photoquadrat was divided into sixteen $12 \mathrm{~cm} \times 12 \mathrm{~cm}$ sections which were individually photographed, and percent cover was estimated from nine stratified random points per section $(N=144$ point per quadrat). Macroalgae and coral were identified to genus or species while other organisms were identified to functional group (e.g., sponges, gorgonians, turf algae, crustose coralline algae). For turf algae, we also determined whether a point landed on an algal filament or sediment bound in the turf.

\section{Questions and analyses}

Our goals were to identify differences in foraging behavior and resource use among the nine species of parrotfish and to test the extent that each species exhibits a unique combination of foraging traits. To achieve this we: (1) investigated the degree that species differed in univariate traits (i.e., bite rates, distance travelled while foraging) and multivariate traits (i.e., diet, substrates grazed), (2) tested whether variation among species in foraging traits was related to size and/or genera, and (3) summarized relationships among species in multivariate trait-space.

We used linear mixed models to test for relationships between fish size (as estimated fork length), time of day, and genus on bite rate and the maximum linear distance moved during a 20-min observation. Models included species as a random effect and also tested for interactions between fish size and time of day and genus. Fork length, bite rate, and distance travelled were all log-transformed prior to analyses to satisfy assumptions of the linear models. We then investigated the diet composition of each species using an electivity index (Manly's alpha; Chesson 1983) in order to identify whether particular food items tended to be eaten more or less often than expected based on their relative availability. We determined availability of food items by calculating mean abundance of each food type from point contacts of the major substrates targeted by parrotfishes. Electivity was calculated using weighted means of the percent cover of each food type on each substrate targeted by focal fish. Manly's alpha ranges from 0 to 1 and represents the predicted proportion of each food item included in an individual's diet if all food items were equally available. Differences in habitat selection were also evaluated by calculating an electivity index (Manly's alpha) based on the survey data. Next, differences in diet, substrates grazed, and habitat selection among species were visualized using hierarchical cluster analysis with Ward's linkage on Bray-Curtis dissimilarity matrices of square root transformed data. Differences among major clusters were then tested with permutational MANOVA (Anderson 2001) ( $N=\sim 18$ values per species). Permutation-based contingency tests (i.e., Fisher's exact) were then used to determine whether the different genera of parrotfish were distributed non-randomly among significant clusters.

Finally, to summarize relationships among species in multivariate trait space (combining all traits such as diet, distance moved, substrate targeted, etc.), we first used three separate principal component analyses (PCA) to summarize data on diets, substrates targeted, and habitats selected, respectively, in one or two principal components (which explained at least $74 \%$ of the variance for each resource type; Tables S3, S4, and S5). Next, principal components derived from the three analyses on each resource type were combined with data on bite rates and distance moved while foraging, normalized (mean zero and unit variance), and subjected to a redundancy analysis (RDA; Legendre and Legendre 2012), which ordinated species according to their combined trait values. Analyses were conducted in the $\mathrm{R}$ programing language using the vegan package (Oksanen et al. 2013) for multivariate analyses and the nlme (Pinheiro et al. 2013) and lmmfit (Maj 2011) packages for mixed effects models. All data are available from NOAA National Centers for Environmental Information: http:// accession.nodc.noaa.gov/0127525 (Adam et al. 2015b).

\section{Results}

\section{Parrotfish community structure}

Shallow, high-relief habitat on spur and groove reefs was dominated numerically by three species of parrotfishes, 
Fig. 1 Mean density and biomass $(+\mathrm{SE})$ of nine species of parrotfish on $(\mathbf{a}, \mathbf{d})$ high relief reef, (b, e) low relief reef, and $(\mathbf{c}, \mathbf{f})$ boulder and rubble habitat $(N=4$ sites $)$
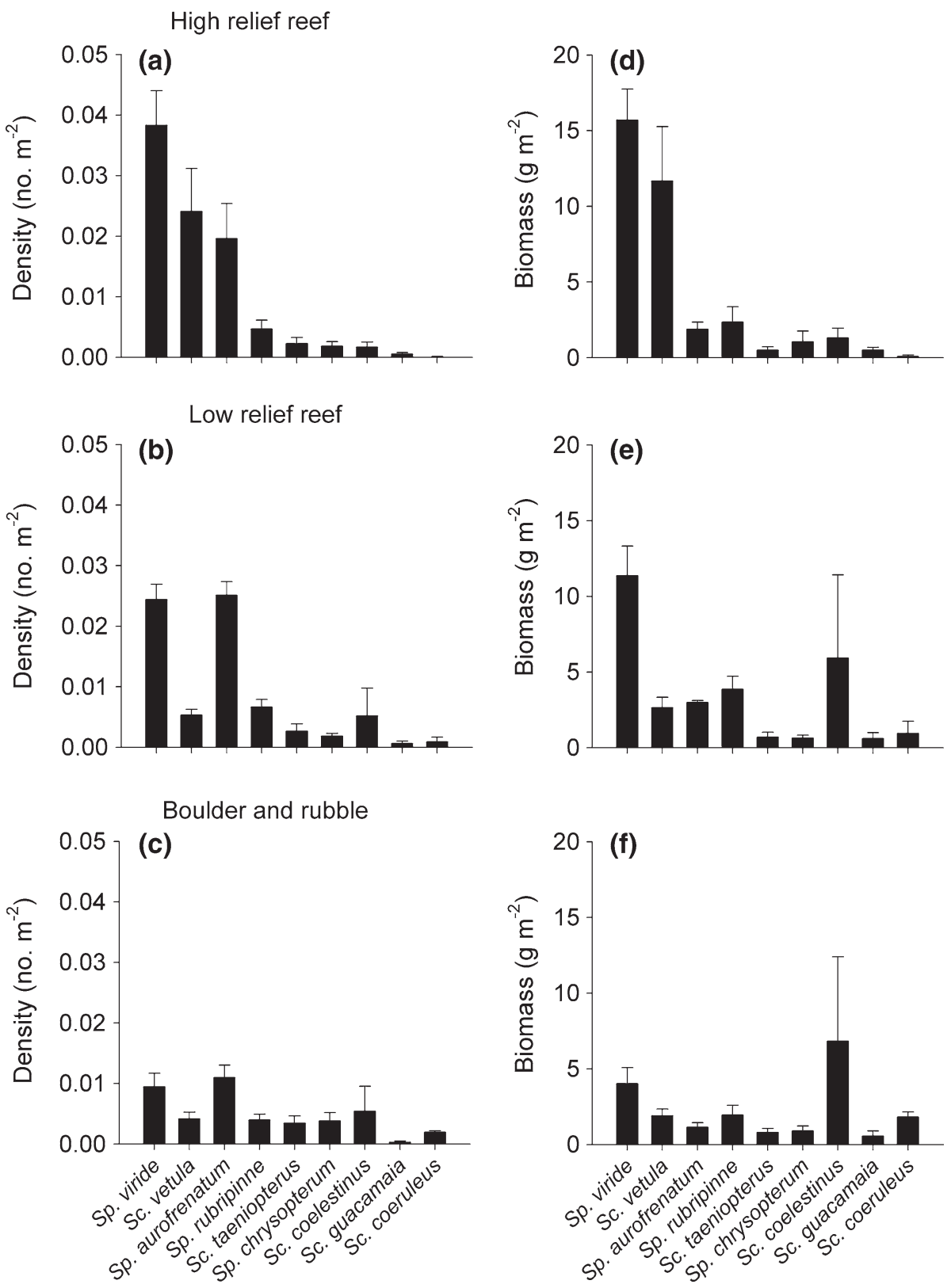

Species

$S p$. viride, Sc. vetula, and Sp. aurofrenatum, with lowrelief hardbottom dominated by two of these ( $S p$. viride and Sp. aurofrenatum) (Fig. 1). Sp. viride and Sp. aurofrenatum were also the most abundant species in the boulder and rubble habitat, although this habitat had a more even mix of all nine species. Sc. guacamaia and Sc. coeruleus were the least abundant species in all habitats; however, both species contributed a non-trivial amount of biomass to the entire parrotfish assemblage due to their large size (2 and $3 \%$, respectively, compared to $7 \%$ by numerically abundant but much smaller Sp. aurofrenatum).

\section{Diet and feeding ecology}

Both within and between genera, focal fishes varied greatly in size, bite rate, and distance moved (Fig. S2). There was a significant interaction between genus and fish length on bite rate (ANOVA, $F_{1,149}=7.40, P=0.007$ ). Fish length and time of day both predicted bite rates of Scarus parrotfishes (full model $R^{2}=0.52$ ), with bite rates decreasing with length (ANOVA, $F_{1,82}=21.8, P<0.001$; Fig. 2a) and increasing throughout the day (ANOVA, $F_{1,82}=12.88$, $P<0.001)$. In contrast, bite rates of Sparisoma parrotfishes (full model $R^{2}=0.08$ ) showed no correlation with 
Fig. 2 Relationship between length and bite rate for (a) Scarus and (b) Sparisoma parrotfishes, showing different relationships for each genus. Relationship between length and the maximum linear distance moved during an observation for (c) Scarus and (d) Sparisoma parrotfishes showing different relationships for each genus. Note the log scale on all graphs $(N=\sim 18$ individuals per species; see Table S2 for exact sample sizes)
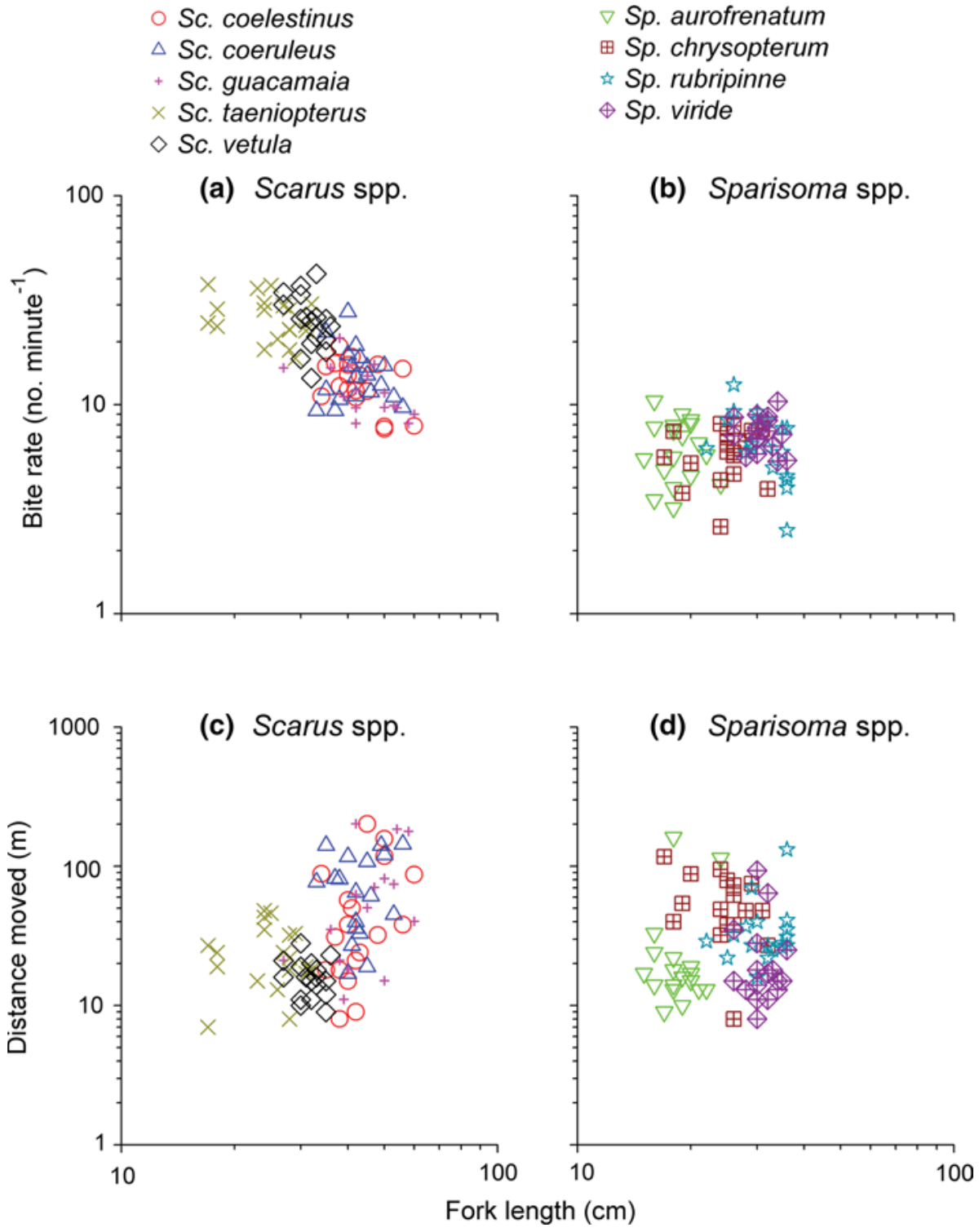

$\nabla$ Sp. aurofrenatum

$\boxplus$ Sp. chrysopterum

is Sp. rubripinne

$\oplus$ Sp. viride

(b) Sparisoma spp.

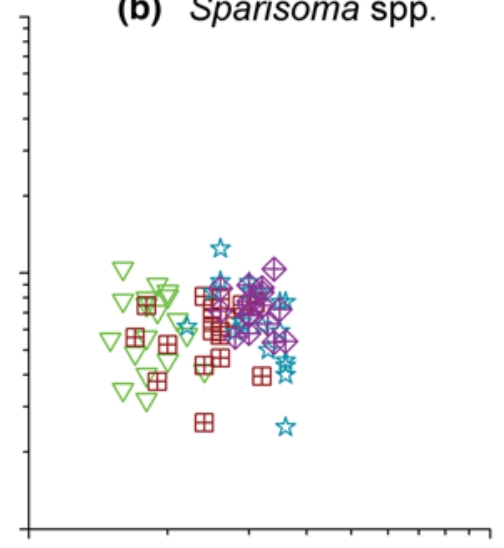

(d) Sparisoma spp. 0 length (ANOVA, $F_{1,67}=0.042, P=0.84$; Fig. 2b), but a weak positive correlation with time of day (ANOVA, $\left.F_{1,67}=6.09, P=0.016\right)$.

There was also a significant interaction between genus and fish length on the distance moved during an observation (ANOVA, $F_{1,147}=5.41, P=0.021$ ). For Scarus parrotfishes, there was a significant positive correlation between length and distance moved (ANOVA, $F_{1,80}=11.76, P=0.001$; Fig. $2 \mathrm{c}$ ), but no effect of time of day (ANOVA, $F_{1,80}=1.75, P=0.19$ ). For Sparisoma parrotfishes, there was no correlation between either length (ANOVA, $F_{1,67}=0.007, P=0.93$; Fig. 2 d) or time of day (ANOVA, $F_{1,67}=0.683, P=0.41$ ) and distance moved.

EAM was the dominant food item on all substrate types, followed by brown macroalgae (primarily Dictyota spp.; Fig. S3a). Within the EAM complex, pavement, boulder, and rubble had high sediment levels with low cover of
CCA while sediment levels were lower and CCA higher on dead coral and ledges (Fig. S3). Parrotfishes fed primarily on the dominant food types (EAM and brown macroalgae). However, electivity indexes revealed that many parrotfishes also targeted less common types of macroalgae. For example, Sp. chrysopterum selected for red calcareous algae while Sp. aurofrenatum targeted green calcareous algae and $S c$. guacamaia fed selectively on scleractinian corals and sponges (Fig. S4). Analysis of parrotfish diets revealed two distinct clusters of parrotfishes (PerMANOVA, Pseudo $F_{1,160}=230, P<0.001$; Fig. 3) with fish in the same genus tending to have similar diets (Fisher's exact test $P=0.048)$. Sparisoma viride clustered with the Scarus parrotfishes, which fed primarily on EAM and endolithic algae. The three remaining species of Sparisoma formed a single cluster due to their tendency to feed on macroalgae, especially brown macroalgae (mainly Dictyota spp.). 


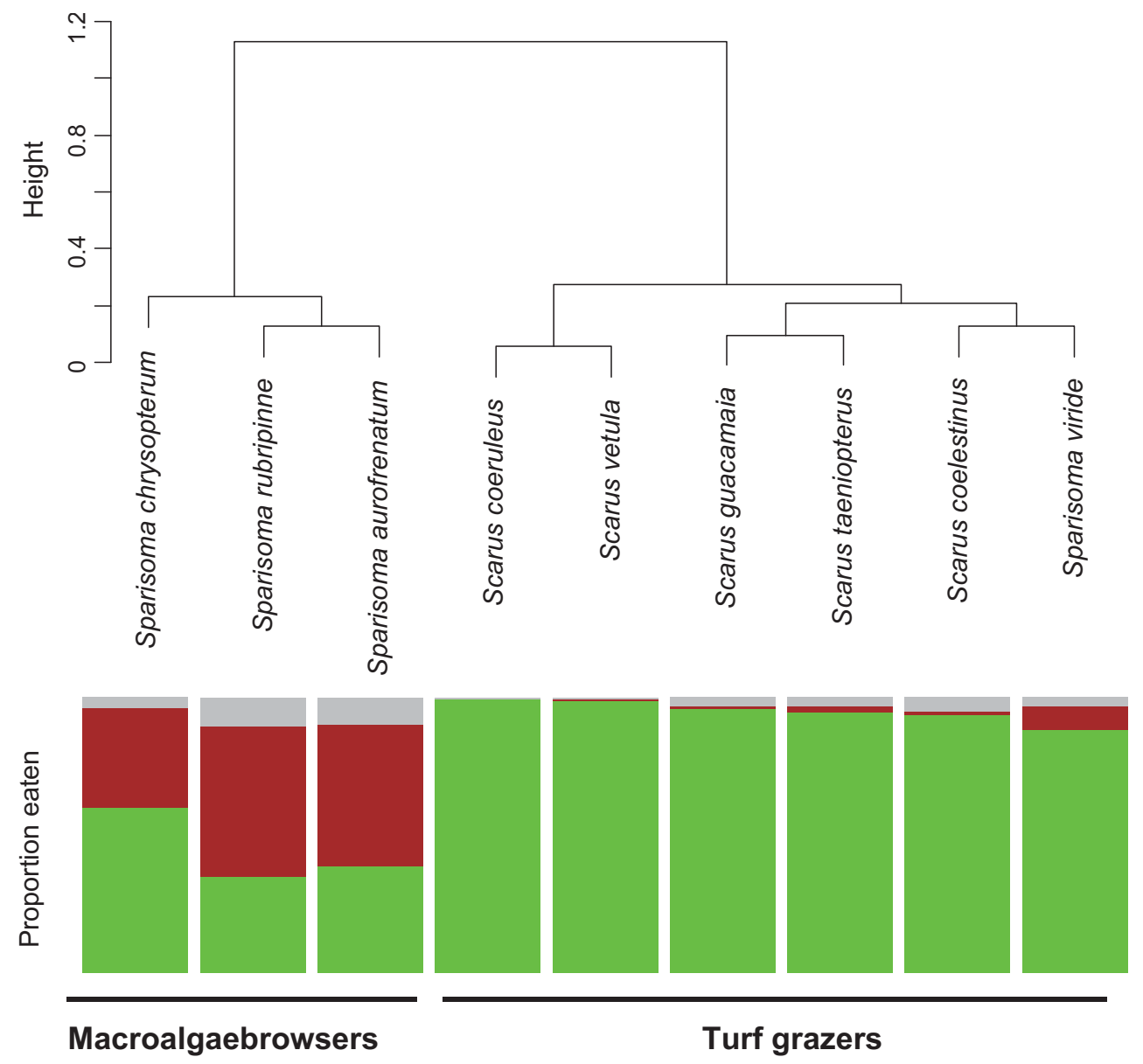

Turf algae and CCA (EAM)
Brown macroalgae
Other

Fig. 3 Species-averaged dendogram showing that parrotfishes cluster into two groups based on their diets. Sp. chrysopterum, $S p$. rubripinne, and Sp. aurofrenatum feed largely on brown macroalgae (mainly Dictyota spp.), while fishes in the genus Scarus and

While all species of parrotfishes targeted all major substrate types to some extent, multivariate analyses revealed three distinct clusters of species based on the substrates they targeted. The most distinct of these was a cluster consisting of Sc. coeruleus, Sc. taeniopterus, and Sp. chrysopterum, which primarily targeted carbonate boulders and coral rubble (Pseudo $F_{1,160}=38.7, P<0.001$; Fig. 4). Of the remaining six species, two clusters were evident, with $S c$. vetula and $S p$. viride primarily targeting dead coral substrate, and Sc. coelestinus, Sp. aurofrenatum, Sc. guacamaia, and Sp. rubripinne targeting a relatively equal proportion of all major substrate types (Pseudo $F_{1,104}=8.82$, $P<0.001$; Fig. 4). Scarus and Sparisoma parrotfishes were
Sp. viride feed primarily on filamentous turfs, endolithic algae, and CCA. Bar charts show the mean proportion of each food item targeted $(N=\sim 18$ individuals per species; see Table $\mathrm{S} 2$ for exact sample sizes). See Fig. S4 for less common food items and electivity values

randomly distributed across the three clusters (Fisher's exact, $P=1)$.

\section{Habitat selection}

While all parrotfishes were observed in all habitat types (Fig. 1), surveys revealed that different species exhibited distinct preferences for particular habitats (Fig. 5). Multivariate analyses revealed two distinct clusters of parrotfishes based on habitat preferences (Pseudo $F_{1,34}=10.51$, $P<0.001$; Fig. 5), with Scarus and Sparisoma parrotfishes randomly distributed across each (Fisher's exact test, $P=0.357$ ). The first cluster, consisting of $S c$. 


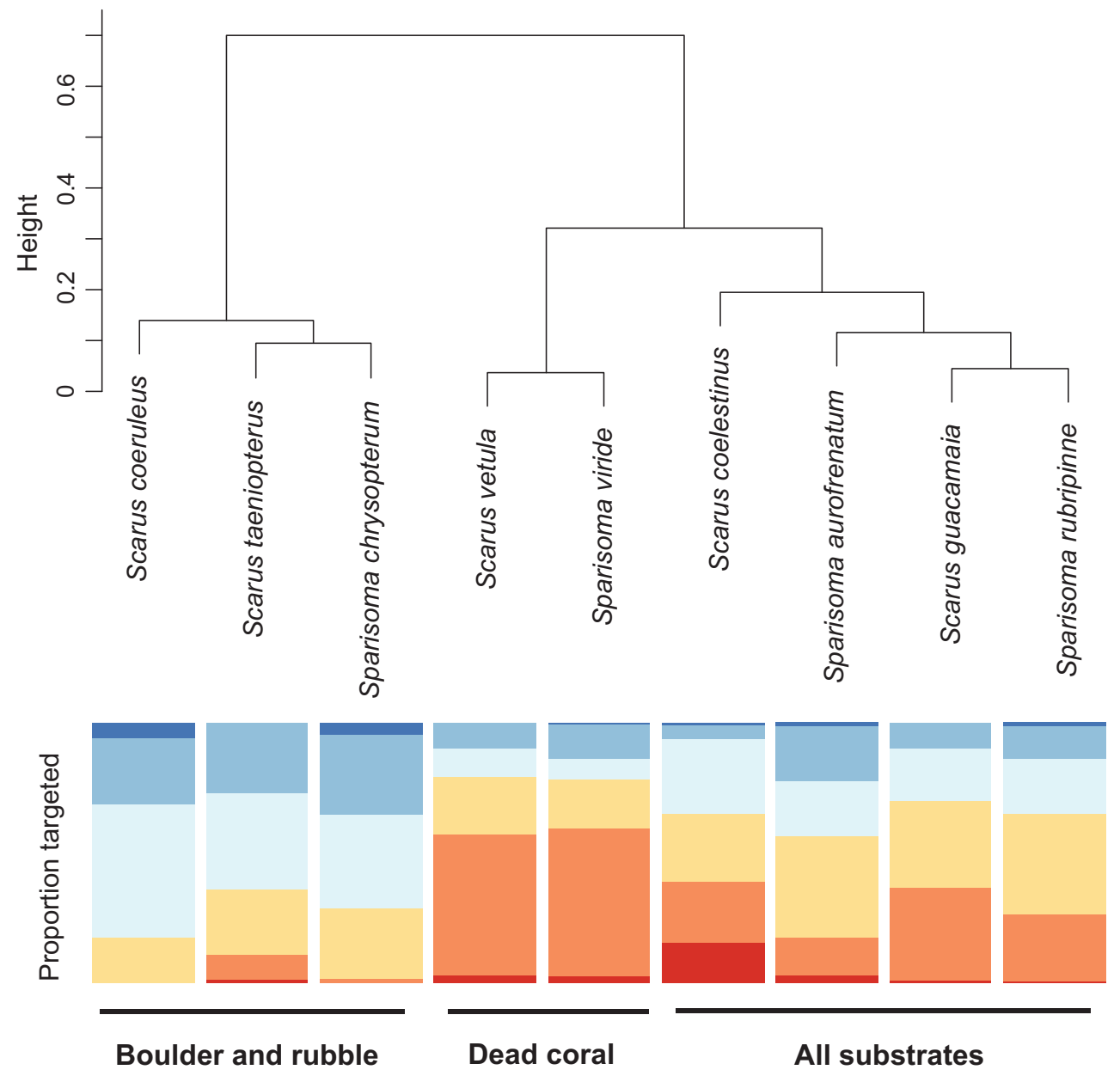

\begin{tabular}{l|l|}
\hline Ledge & Boulder \\
Dead coral & Rubble \\
Pavement & Sand \\
\hline
\end{tabular}

Fig. 4 Species-averaged dendogram showing that parrotfishes cluster into three groups based on the substrates they target while foraging. $S c$. coeruleus, Sc. taeniopterus, and $S p$. chrysopterum primarily target carbonate boulder and coral rubble substrate. Sc. vetula and Sp. vir-

vetula, Sp. viride, Sc. guacamaia, Sp. aurofrenatum, and Sp. rubripinne tended to avoid boulder and rubble habitat. The second cluster, consisting of Sc. coeruleus, Sc. taeniopterus, Sc. coelestinus, and Sp. chrysopterum tended to preferentially associate with boulder and rubble habitat (Fig. 5).

\section{Trait diversity}

The RDA captured the majority of variance in traits in the first two axes, with these axes accounting for 47 and $38 \%$ of the variance, respectively (Table S6). Differences in diet were mainly captured by RDA 2 , with species that ide primarily target dead coral. Sc. coelestinus, Sp. aurofrenatum, Sc. guacamaia, and Sp. rubripinne target all substrates. Bar charts show the mean proportion of each substrate targeted $(N=\sim 18$ individuals per species; see Table S2 for exact sample sizes)

feed primarily on turf algae having high values and species that feed primarily on macroalgae having low values (Fig. 6). In contrast, RDA 1 primarily captured differences in the spatial patterning of foraging, with species that travelled long distances and preferred boulder and rubble habitats having low values, and species that travelled short distances and preferred high relief habitat having high values (Fig. 6). While there was relatively little overlap between species that feed on macroalgae and those that primarily feed on EAM, there was overlap between some species within each of these groups. Among macroalgal browsers, there was extensive overlap between $S p$. aurofrenatum and $S p$. rubripinne; among turf grazers there was high overlap 


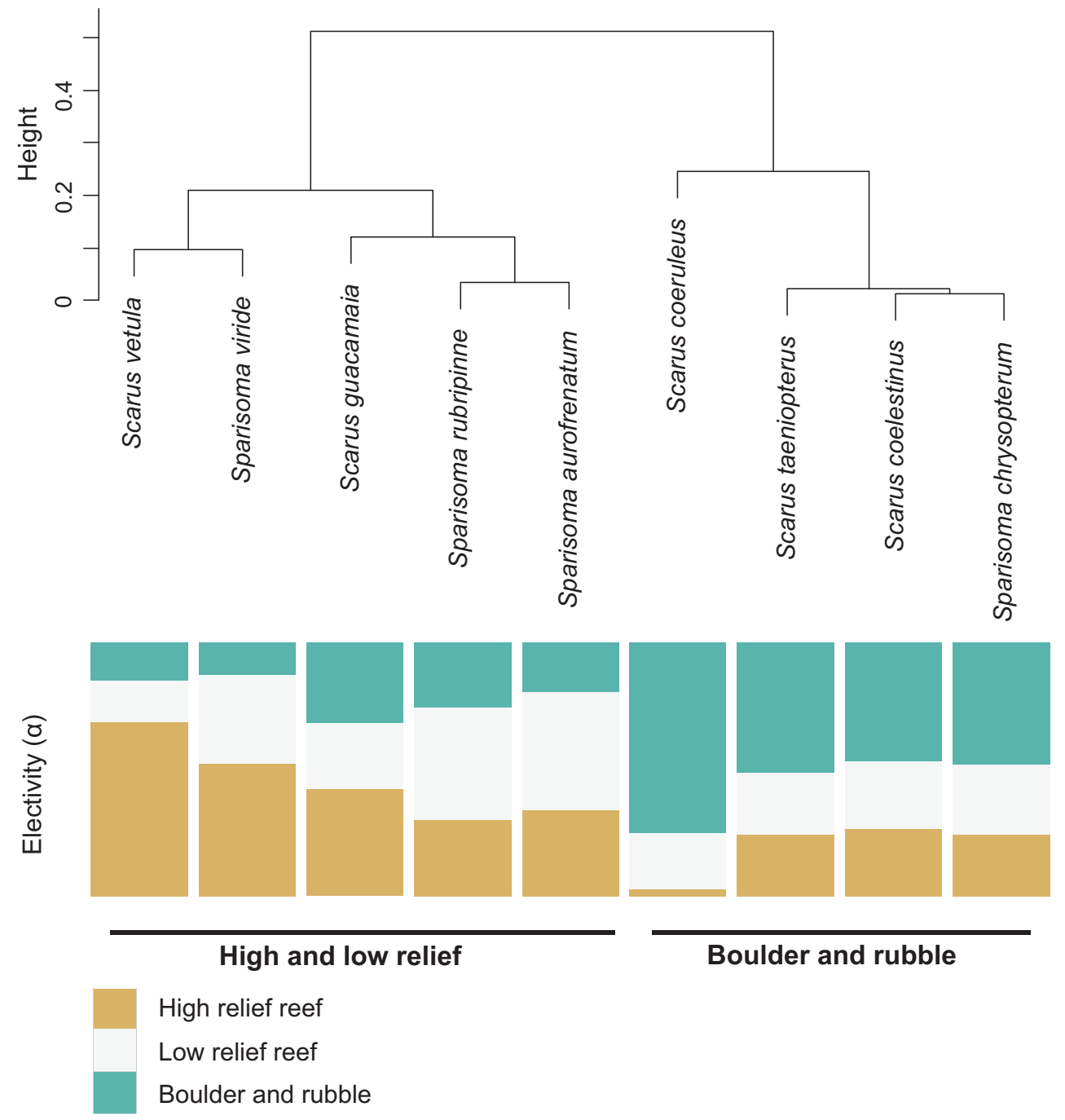

Fig. 5 Species-averaged dendogram showing clustering of species based on electivity values for high relief, low relief, and boulder and rubble habitats from survey data. Species cluster into two significant groups, with Sc. coeruleus, Sc. taeniopterus, Sc. coelestinus, and Sp.

between Sc. guacamaia and Sc. coelestinus. Three of the turf grazers, $S c$. vetula, $S p$. viride, and $S c$. coeruleus exhibited little overlap with other species (Fig. 6).

\section{Discussion}

Herbivorous fishes can enhance the resilience of coraldominated reefs by preventing the establishment and proliferation of algae that otherwise negatively impact coral settlement, growth, and survivorship (Hughes et al. 2007; Adam et al. 2011). Yet we are only beginning to understand the level of functional diversity present within the herbivore guild (Burkepile and Hay 2008; Hoey and Bellwood 2009; Rasher et al. 2013). In this study, we observed chrysopterum preferring boulder and rubble habitats, and all other species tending to avoid this habitat. Bar charts show mean electivity values for different habitat types ( $N=4$ sites)

large functional differences among herbivorous parrotfishes when we considered both diet and other important metrics like habitat selection and preferred feeding substrate. With one exception, parrotfishes belonging to the same genus fed on similar types of algae, suggesting that they may be functionally redundant in what they eat. However, species with similar diets were dissimilar in other attributes, such as the habitats they frequented or the types of substrate they fed from. These differences indicate that species that appear to be functionally redundant when looking at diet alone exhibit high levels of complementarity when we consider multiple functional traits that determine species' niches.

Previous work suggests that the diets of different genera of parrotfishes are often complementary. For example, Burkepile and Hay (2008, 2010) demonstrated 


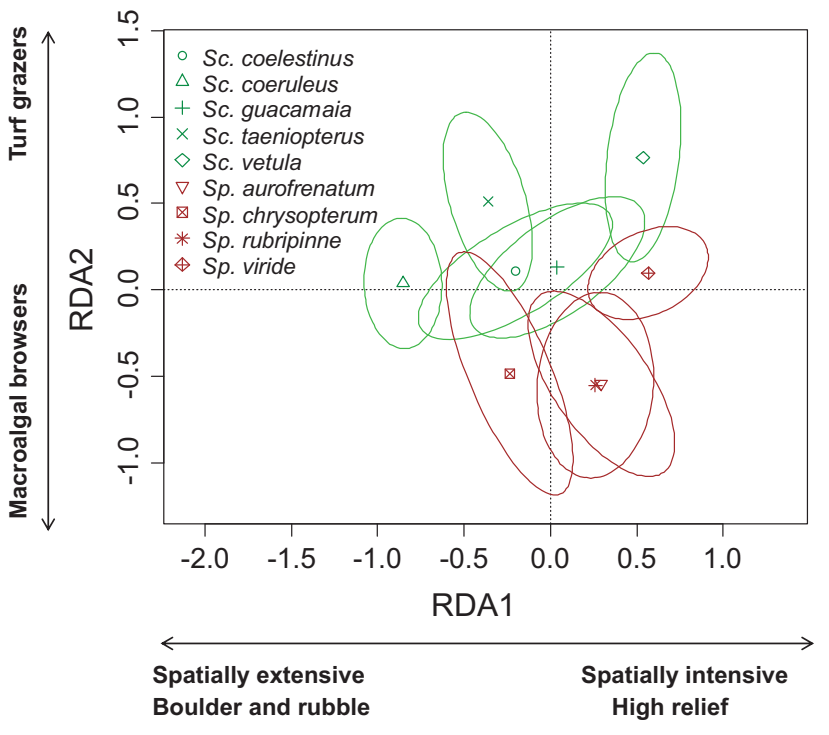

Fig. 6 Ordination plot from redundancy analysis (RDA) of all foraging traits (i.e., bite rate, foraging range, diet, substrates targeted, and habitat preferences). Centroids for each species are plotted with dispersion ellipses using 0.9 confidence limits of the standard deviation of species scores. Fishes that feed primarily on EAM (turf grazers) have higher values of RDA 2 than those that feed on macroalgae. RDA 1 primarily captured differences in the spatial patterning of foraging, with spatially intensive foragers that prefer high relief habitat where they feed on dead coral having positive values, and spatially extensive foragers that prefer boulder and rubble habitat having negative values $(N=\sim 18$ individuals per species; see Table $\mathrm{S} 2$ for exact sample sizes)

experimentally that $S p$. aurofrenatum and Sc. taeniopterus suppress algae more effectively together than either species can alone. However, these results were context-dependent with Sc. taeniopterus controlling filamentous algal turfs and preventing the establishment of macroalgae in early successional stage communities. Yet $S p$. aurofrenatum prevented the spread and proliferation of macroalgae in later successional stage communities with high abundances of macroalgae, but had little impact on algal communities in early stages of succession. Our results indicate similar levels of diet complementarity among most species of Sparisoma and Scarus parrotfishes. The three species of Sparisoma parrotfishes that fed on significant amounts of brown macroalgae will be important for preventing macroalgae from encroaching and overgrowing corals and may help reverse phase shifts on macroalgal-dominated reefs. In contrast, Scarus parrotfishes and Sp. viride, which favor algal turfs, crustose coralline algae, and endolithic algae, can prevent the establishment of macroalgae and create bare space that can be colonized by coral larvae following a disturbance. Thus, a mix of species from each genus will likely be necessary to simultaneously prevent the spread of harmful algae and facilitate coral recruitment and growth.
When considered alone, our observations of diet among Caribbean parrotfishes suggest high levels of functional redundancy within each genus. However, in addition to knowing what different herbivores are eating, we also need to understand how their impacts are distributed in space. We found that species with similar diets often foraged in different locations on the reef. For example, both Sc. vetula and Sc. coeruleus targeted turf algae almost exclusively, but they foraged in different areas and targeted different substrates. Sc. vetula occupied small territories in high-relief areas where they fed predominantly on dead coral dominated by sparse turfs and CCA. But Sc. coeruleus roved over larger areas feeding on algal turfs with high sediment loads growing on loose coral rubble and carbonate boulders. Similarly, Sp. chrysopterum and Sp. rubripinne both fed on significant amounts of brown macroalgae, but $S p$. rubripinne frequently fed from dead coral in high relief areas while Sp. chrysopterum primarily fed from unconsolidated coral rubble and carbonate boulders. Closely related herbivores with similar diets and foraging modes may, therefore, have fundamentally different impacts on reef ecosystems due to different habitat preferences and preferred feeding substrate.

Variation in where herbivores forage is likely to have important consequences for the maintenance and recovery of coral-dominated reefs since some locations within a reef will be more suitable for the growth and recruitment of corals and algae than others. Species that feed intensely in high relief areas, such as $S c$. vetula and $S p$. viride, may be especially important for creating and maintaining habitat suitable for coral recruitment. In contrast, species that preferentially associate with boulder and rubble habitat may be functionally less important since they tend to feed on algae growing on unstable coral rubble and carbonate boulders with high sediment loads which are poor habitat for corals (Birrell et al. 2005).

Differences in the movement behavior of herbivores can also impact the spatial patterning of primary producer communities, a phenomenon that has been well studied in grassland systems (Bakker et al. 1984; Adler et al. 2001; de Knegt et al. 2008). For example, on the African savannah, grazing by ungulates can stimulate productivity of grasses. As a result, grazers frequently revisit previously grazed patches, thereby creating mosaics of short, high-quality grass interspersed with lightly grazed, low-quality patches (McNaughton 1984). Similarly, in California grasslands, intense grazing by pocket gophers facilitates the long-term persistence of annual plants within their territories, while in the absence of grazing, the remaining landscape becomes dominated by late successional perennial species that deter colonization by gophers (Seabloom and Richards 2003). In both cases, positive feedback between grazing and forage 
quality interact with herbivore behavior to create persistent landscape scale patterns of heterogeneity in plant communities. Similar dynamics are likely in play on coral reefs, where intense grazing by territorial species such as $S c$. vetula may help maintain algal communities in a highly palatable state dominated by fast-growing filamentous turf algae with high cover of $\mathrm{CCA}$ which can facilitate coral recruitment. In contrast, grazing by more wide-ranging fishes, such as Sc. coeruleus, is less likely to create the same positive feedbacks unless overall grazing levels are very high, or fishes consistently return to the same patches to forage (Sandin and McNamara 2012).

The high levels of complementarity and low levels of redundancy we observed among Caribbean parrotfishes suggests that loss of any single species is likely to result in the loss of some function. However, predicting the impact of species losses on ecosystem function requires understanding the degree of plasticity in a specie's functional traits. If plasticity is high and species adjust their traits in response to competitors, competition could lead to underestimates of a species functional niche. For example, complementarity in habitat use could be driven by interference competition, with competitively dominant species excluding subordinate species from the highest quality habitats (e.g., Robertson and Gaines 1986). We observed many aggressive interactions between parrotfishes (146 in 162 focal observations), suggesting that competition was intense and that habitat use may be influenced by competitive interactions. Most aggressive interactions (95\%) occurred between species in the same genus (which had largely overlapping diets), and the majority (60\%) were interspecific, suggesting that competition for food may drive closely related species to forage in different habitats and target different substrates. Many of the aggressive interactions we observed involved $S c$. vetula aggressively defending their small territories in high-relief habitat. Substrate in the high-relief habitat was dominated by sparse turfs with low levels of sediments and macroalgae, a high quality diet relative to more highly sedimented turfs or dense macroalgae that often grew on coral rubble and lowrelief hardbottom (Reinthal and Lewis 1986; McClanahan et al. 2000; Bellwood and Fulton 2008). Thus, it appears likely that $S c$. vetula excludes other turf grazers from highrelief habitat, and the loss of Sc. vetula could result in the expansion of the functional niches of its competitors. Alternatively, the loss of $S c$. vetula could result in a reduction in grazing intensity in these high-relief areas if other species only partially compensated for the high levels of herbivory by $S c$. vetula in these habitats. Future work aimed at understanding how competition alters diet and habitat use would be especially useful for understanding the amount of redundancy present within the parrotfish guild.
Patterns of functional redundancy and complementarity could also vary with benthic community composition. Indeed, while our observations of diet are broadly consistent with previous examinations of subsets of Caribbean parrotfishes in other locations (Randall 1967; Lewis 1985; Lewis and Wainwright 1985; Bruggemann et al. 1994; McAfee and Morgan 1996; Cardoso et al. 2009; Burkepile and Hay 2010), the particular types of algae targeted by species can vary greatly among systems. For example, Burkepile and Hay (2011) found that large Scarus species, including Sc. coelestinus, Sc. guacamaia, and Sc. vetula all apparently fed preferentially on articulated red coralline algae that grew in experimental herbivore exclosures. These observations suggest that large Scarus species may be more similar to Sparisoma species than they are to smaller Scarus species (such as Sc. taeniopterus) with regards to their strong preferences for some types of erect calcified macroalgae. Work on large Scarus parrotfishes in the Indo-Pacific also indicate that these 'scraping and excavating grazers' frequently preferentially browse on some types of erect calcified red and green algae when given the chance (Mantyka and Bellwood 2007; Rasher et al. 2013; Hamilton et al. 2014). These data suggest that the foraging patterns of some species may be quite flexible and that studies using behavioral observations to document feeding only on the common algal species may overestimate similarity in the diet preferences among species. Our electivity analyses support these ideas as several parrotfishes targeted relatively rare algal taxa such as articulated red coralline algae. Understanding which species control these rarer algal taxa is important as these typically rare species are often the taxa that come to dominate areas when levels of herbivory are reduced (e.g., Burkepile and Hay 2008). Thus, more detailed work on how diet preferences change across varying levels of algal community composition are needed to help resolve these relationships.

Scientists and managers increasingly recognize the importance of functional diversity for maintaining healthy resilient ecosystems (Peterson et al. 1998; Bellwood et al. 2004; Cadotte et al. 2011). Species are being lost from many ecosystems at an alarming rate, with large consumers often the first to go (Dirzo et al. 2014; McCauley et al. 2015). Predicting the impact of species losses on ecosystem function, therefore, requires knowing how much functional diversity exists within consumer assemblages. We found high levels of functional diversity among Caribbean parrotfishes, key herbivores that facilitate reef-building corals. While closely related species had similar diets, they preferred different habitats, fed from different substrates, and foraged at different spatial scales. Subtle differences in habitat selection and the spatial scale of foraging will strongly modify feedbacks 
between herbivores, algae, and corals, emphasizing the need to consider multiple functional traits when predicting the impact of species losses in high diversity systems. By identifying key functional differences among Caribbean parrotfishes, this study provides critical information needed to manage parrotfishes to enhance the resilience of coraldominated reefs and reverse phase shifts on algal-dominated reefs throughout the wider Caribbean.

Acknowledgments This work was supported by a grant from the NOAA Coral Reef Conservation Program to BIR and DEB and facilitated by grant number OCE-1130786 from the National Science Foundation to DEB and R. Vega Thurber. We thank Laura Catano for assistance with fieldwork and Andrew Hoey and one anonymous reviewer for comments that improved the manuscript. This work was conducted with permission from the Florida Keys National Marine Sanctuary under permit no. FKNMS-2013-058. The authors have no conflicts of interest to declare.

Author contribution statement TCA designed the study with input from DEB and BIR. TCA and MK conducted field work. TCA developed methodology and performed analyses. TCA and DEB wrote the manuscript; BIR provided editorial advice.

\section{References}

Adam TC, Schmitt RJ, Holbrook SJ et al (2011) Herbivory, connectivity, and ecosystem resilience: response of a coral reef to a large-scale perturbation. PLoS One 6:e23717. doi:10.1371/journal.pone. 0023717

Adam TC, Burkepile DE, Ruttenberg BI, Paddack MJ (2015a) Herbivory and the resilience of Caribbean coral reefs: knowledge gaps and implications for management. Mar Ecol Prog Ser 520:1-20. doi:10.3354/meps 11170

Adam TC, Kelley M, Ruttenberg BI, Burkepile DE (2015) Abundance and behavior of parrotfishes (Labridae, Scarinae) in the upper Florida Keys from 2013-06-19 to 2013-07-30 (NODC Accession 0127525)

Adler PB, Raff DA, Lauenroth WK (2001) The effect of grazing on the spatial heterogeneity of vegetation. Oecologia 128:465-479. doi:10.1007/s004420100737

Alvarez-Filip L, Côté IM, Gill JA et al (2011) Region-wide temporal and spatial variation in Caribbean reef architecture: is coral cover the whole story? Glob Chang Biol 17:2470-2477. doi:10.1111/j.1365-2486.2010.02385.x

Anderson MJ (2001) A new method for non-parametric multivariate analysis of variance. Austral Ecol 26:32-46

Bakker J, de Leeuw J, van Wieren S (1984) Micro-patterns in grassland vegetation created and sustained by sheep-grazing. Plant Ecol 55:153-161

Bellwood DR, Fulton CJ (2008) Sediment-mediated suppression of herbivory on coral reefs: decreasing resilience to rising sealevels and climate change? Limnol Oceanogr 53:2695-2701. doi:10.4319/lo.2008.53.6.2695

Bellwood DR, Hughes TP, Folke C, Nyström M (2004) Confronting the coral reef crisis. Nature 429:827-833. doi:10.1038/nature02691

Bellwood DR, Hughes TP, Hoey AS (2006) Sleeping functional group drives coral-reef recovery. Curr Biol 16:2434-2439. doi:10.1016/j. cub.2006.10.030

Birrell CL, McCook LJ, Willis BL (2005) Effects of algal turfs and sediment on coral settlement. Mar Pollut Bull 51:408-414. doi:10.1016/j.marpolbul.2004.10.022
Bohnsack JA, Harper DE (1988) Length-weight relationships of selected marine reef fishes from the southeastern United States and the Caribbean. NOAA technical memorandum NMFS-SEFC-215, pp 1-31

Bohnsack JA, Harper DE, Mcclellan DB (1994) Fisheries trends from Monroe County, Florida. Bull Mar Sci 54:982-1018

Bonaldo RM, Hoey AS, Bellwood DR (2014) The ecosystem roles of parrotfishes on tropical reefs. Oceanogr Mar Biol An Annu Rev 52:81-132

Bozec Y-M, Alvarez-Filip L, Mumby PJ (2015) The dynamics of architectural complexity on coral reefs under climate change. Glob Chang Biol 21:223-235. doi:10.1111/gcb.12698

Brandl SJ, Bellwood DR (2014) Individual-based analyses reveal limited functional overlap in a coral reef fish community. J Anim Ecol 83:661-670. doi:10.1111/1365-2656.12171

Bruggemann JH, Kuyper MWM, Breeman AM (1994) Comparative analysis of foraging and habitat use by the sympatric Caribbean parrotfish Scarus vetula and Sparisoma viride (Scaridae). Mar Ecol Prog Ser 112:51-66

Bruno JF, Sweatman H, Precht WF (2009) Assessing evidence of phase shifts from coral to macroalgal dominance on coral reefs. Ecology 90:1478-1484

Burkepile DE, Hay ME (2008) Herbivore species richness and feeding complementarity affect community structure and function on a coral reef. Proc Natl Acad Sci USA 105:16201-16206. doi:10.1073/ pnas.0801946105

Burkepile DE, Hay ME (2010) Impact of herbivore identity on algal succession and coral growth on a Caribbean reef. PLoS One 5:e8963. doi:10.1371/journal.pone.0008963

Burkepile DE, Hay ME (2011) Feeding complementarity versus redundancy among herbivorous fishes on a Caribbean reef. Coral Reefs 30:351-362. doi:10.1007/s00338-011-0726-6

Cadotte MW, Carscadden K, Mirotchnick N (2011) Beyond species: functional diversity and the maintenance of ecological processes and services. J Appl Ecol 48:1079-1087. doi:10.1111/j.1365-2664.2011.02048.x

Cardoso SC, Soares MC, Oxenford HA, Côté IM (2009) Interspecific differences in foraging behaviour and functional role of Caribbean parrotfish. Mar Biodivers Rec 2:e148. doi:10.1017/ S1755267209990662

Carpenter RC (1986) Partitioning herbivory and its effects on coral reef algal communities. Ecol Monogr 56:345-364

Chesson J (1983) The estimation and analysis of preference and its relatioship to foraging models. Ecology 64:1297-1304

De Knegt HJ, Groen TA, van de Vijver CADM et al (2008) Herbivores as architects of savannas: inducing and modifying spatial vegetation patterning. Oikos. doi:10.1111/j.2008.0030-1299.16403.x

Dirzo R, Young H, Galetti M, Ceballos G (2014) Defaunation in the Anthropocene. Science 345:401-406

Du Toit JT, Cumming DHM (1999) Functional significance of ungulate diversity in African savannas and the ecological implications of the spread of pastoralism. Biodivers Conserv 8:1643-1661

Duffy JE (2002) Biodiversity and ecosystem function: the consumer connection. Oikos 99:201-219. doi:10.1034/j.1600-0706.2002.990201.x

Edwards CB, Friedlander AM, Green AG et al (2014) Global assessment of the status of coral reef herbivorous fishes: evidence for fishing effects. Proc R Soc B Biol Sci 281:20131835. doi:10.1098/rspb.2013.1835

Estes JA, Terborgh J, Brashares JS et al (2011) Trophic downgrading of planet Earth. Science 333:301-306. doi:10.1126/ science. 1205106

Folke C, Carpenter S, Walker B (2004) Regime shifts, resilience, and biodiversity in ecosystem management. Annu Rev Ecol Evol Syst 35:557-581. doi:10.2307/annurev.ecolsys.35.021103.30000021

Hamilton SL, Smith JE, Price NN, Sandin SA (2014) Quantifying patterns of fish herbivory on Palmyra Atoll (USA), an uninhabited 
predator-dominated central Pacific coral reef. Mar Ecol Prog Ser 501:141-155. doi:10.3354/meps10684

Hawkins JP, Roberts CM (2003) Effects of fishing on sex-changing Caribbean parrotfishes. Biol Conserv 115:213-226. doi:10.1016/ S0006-3207(03)00119-8

Hoey AS, Bellwood DR (2009) Limited functional redundancy in a high diversity system: single species dominates key ecological process on coral reefs. Ecosystems 12:1316-1328. doi:10.1007/ s10021-009-9291-z

Hughes TP, Rodrigues MJ, Bellwood DR et al (2007) Phase shifts, herbivory, and the resilience of coral reefs to climate change. Curr Biol 17:360-365. doi:10.1016/j.cub.2006.12.049

Hughes TP, Graham NAJ, Jackson JBC et al (2010) Rising to the challenge of sustaining coral reef resilience. Trends Ecol Evol 25:633-642. doi:10.1016/j.tree.2010.07.011

Jackson J, Donovan M, Cramer K, Lam V (eds) (2014) Status and Trends of Caribbean Coral Reefs 1970-2012. Global Coral Reef Monitoring Network c/o International Union for the Conservation of Nature Global Marine and Polar Program, Washington, D. C

Legendre P, Legendre L (2012) Numerical ecology. Third English Edition. Elsevier, Amsterdam

Lewis SM (1985) Herbivory on coral reefs: algal susceptibility to herbivorous fishes. Oecologia 65:370-375

Lewis SM, Wainwright PC (1985) Herbivore abundance and grazing intensity on a Caribbean coral reef. J Exp Mar Bio Ecol $81: 215-228$

Lokrantz J, Nyström M, Thyresson M, Johansson C (2008) The nonlinear relationship between body size and function in parrotfishes. Coral Reefs 27:967-974. doi:10.1007/s00338-008-0394-3

MacArthur R, Levins R (1967) The limiting similarity, convergence, and divergence of coexisting species. Am Nat 101:377-385

Maj A (2011) lmmfit: goodness-of-fit measures for linear mixed models with one-level-grouping. $\mathrm{R}$ package version 1.0

Mantyka CS, Bellwood DR (2007) Macroalgal grazing selectivity among herbivorous coral reef fishes. Mar Ecol Prog Ser 352:177-185. doi:10.3354/meps07055

McAfee ST, Morgan SG (1996) Resource use by five sympatric parrotfishes in the San Blas Archipelago, Panama. Mar Biol 125:427-437

McCauley DJ, Pinsky ML, Palumbi SR et al (2015) Marine defaunation: animal loss in the global ocean. Science 347:1255641. doi:10.1126/science.1255641

McClanahan TR, Bergman K, Huitric M et al (2000) Response of fishes to algae reduction on Glovers Reef, Belize. Mar Ecol Prog Ser 206:273-282. doi:10.3354/meps206273

McNaughton S (1984) Grazing lawns: animals in herds, plant form, and coevolution. Am Nat 124:863-886
Mumby PJ (2006) The impact of exploiting grazers (Scaridae) on the dynamics of Caribbean coral reefs. Ecol Appl 16:747-769

Nash KL, Graham N, Bellwood DR (2013) Fish foraging patterns, vulnerability to fishing and implications for the management of ecosystem function across scales. Ecol Appl 23:1632-1644

Oksanen J, Blanchet FG, Kindt R, Legendre P, Minchin PR, O'Hara RB, Simpson GL, Solymos P, Stevens MHH, Wagner H (2013) vegan: community ecology package. $\mathrm{R}$ package version $2.0-10$

Paddack MJ, Cowen RK, Sponaugle S (2006) Grazing pressure of herbivorous coral reef fishes on low coral-cover reefs. Coral Reefs 25:461-472. doi:10.1007/s00338-006-0112-y

Perry CT, Murphy GN, Kench PS et al (2013) Caribbean-wide decline in carbonate production threatens coral reef growth. Nat Commun 4:1402. doi:10.1038/ncomms2409

Peterson G, Allen C, Holling C (1998) Ecological resilience, biodiversity, and scale. Ecosystems 1:6-18

Pinheiro J, Bates D, DebRoy S, Sarkar D; R Development Core Team (2013). nlme: linear and nonlinear mixed effects models. R package version 3.1-113

Randall JE (1967) Food habits of reef fishes of the West Indies. Stud Trop Oceanogr 5:665-847

Rasher DB, Hoey AS, Hay ME (2013) Consumer diversity interacts with prey defenses to drive ecosystem function. Ecology 94:1347-1358

Reinthal P, Lewis S (1986) Social behaviour, foraging efficiency and habitat utilization in a group of tropical herbivorous fish. Anim Behav 34:1687-1693

Robertson DR, Gaines SD (1986) Interference competition structures habitat use in a local assemblage of coral reef surgeonfishes. Ecology 67:1372-1383

Sandin SA, McNamara DE (2012) Spatial dynamics of benthic competition on coral reefs. Oecologia 168:1079-1090. doi:10.1007/ s00442-011-2156-0

Seabloom E, Richards S (2003) Multiple stable equilibria in grasslands mediated by herbivore population dynamics and foraging behavior. Ecology 84:2891-2904

Steneck RS, Arnold SN, Mumby PJ (2014) Experiment mimics fishing on parrotfish: insights on coral reef recovery and alternative attractors. Mar Ecol Prog Ser 506:115-127. doi:10.3354/ meps 10764

Streelman JT, Alfaro M, Westneat MW (2002) Evolutionary history of the parrotfishes: biogeography, ecomorphology, and comparative diversity. Evolution (N Y) 56:961-971

Wilson SK, Bellwood DR, Choat JH, Furnas MJ (2003) Detritus in the epilithic algal matrix and its use by coral reef fishes. Oceanogr Mar Biol 41(41):279-309 